1958.

9) Oettingen V. Poisoning. New York: Hoeber Harper, 1954.

10) Kitamura $\mathbf{S}$, Ueda $K$, Niino J, et al. Chemical and toxicological studies on Minamata disease. J Kumamoto Med Soc 1960; 34 (Suppl) : 593-601 (in Japanese with English abstract).

11) Takeuchi $T$, Kambara $T$, Morikawa $N$, et al. Pathological observation of the Minamata disease especially in the cause of this disease. $\mathrm{J}$ Kumamoto Med Soc 1960; 34 (Suppl): 521-530 (in Japanese with English abstract).

12) Uchida $M$, Hirakawa $K$, Inoue $T$. Biochemical studies on Minamata disease. IV. Isolation and chemical identification of the mercury compound in the toxic shellfish with special reference to the causal agent of the disease. Kumamoto Med J 1961; 14 : 181-187.

13) Irukayama K, Kai F, Fujiki M, et al. Studies on the origin of the causative agent of Minamata disease. III. Industrial wastes containing mercury compounds from Minamata factory. Kumamoto Med J 1962; $15: 57-68$.

14) Edwards GH. Two cases of poisoning by mercury methide. St Barts Hosp Reports 1865; i: 141-150.

15) Hill, WH. A report on two cases from exposure to the fumes of diethyl mercury. Canad J Pub Health $1943 ; 34: 158-160$.

16) Lundgren K-D, Swensson A. Alkyl mercury compounds as a source of occupational disease. Nord Hyg Toxicol 1948; 29: 1-30.

17) Ahlmark A. Poisoning by methyl mercury compounds. Brit J Ind Med 1948; 5: 117-119.

18) Höök O, Lundgren K-D, Swensson A. On alkyl mercury poisoning. With a description of two cases. Acta Med Scand 1954; 150: 131-137.

19) U1 Hag I. Agrosan poisoning in man. Brit Med J $1963 ; 1: 1579$.

20) Bakir F, Damluzi SF, Amin-Zaki L, et al. Methylmercury poisoning in Iraq. An interuniversity reports. Science $1973 ; 181: 230-241$.

21) Derban LKA. Outbreak of food poisoning due to alkylmercury fungicide on Southern Ghana state farm. Arch Environ Health 1974; 28 : 49.

22) Bidstrup PL. Toxicity of mercury and its compounds. New York: Elservier, 1964: 85-109.

23) Zangger H. Erfahrungen über Quecksilver vergiftungen. Arch Gewerbepath Gewerbehyg 1930; 1: 539-560.

24) Koelsch F. Gesundheitsschädigungen durch organische Quecksilber verbindungen. Arch Gewerbepath Gewerbeheyg 1937; 8: 113-116.

25) Nagano S, Kida T, Harada $Y$, et al. Minamata disease in children. J Kumamoto Med Soc 1960; 34 (Suppl): 511-530 (in Japanese with English abstract).

26) Inaoka $T$, Nagano $M$. Reproductive histories of coastal and inland women with and without exposure to methylmercury in Kumamoto. Jpn J Hyg 1995; 50: 861-866.

27) WHO. IPCS. Environmental health criteria 101 methylmercury. Geneva: WHO, 1990.

28) Futatsuka $M$, Kitano $T$, Inaoka $T$, et al. Recent findings of epidemiological features of Minamata disease. Environ Sciences 1994; 3: 1-14.

29) Arima S. Minamata Disease from the view of the chisso production process. Minamata Disease. Tokyo: Seirinsha, 1979, 153-198 (in Japanese). 


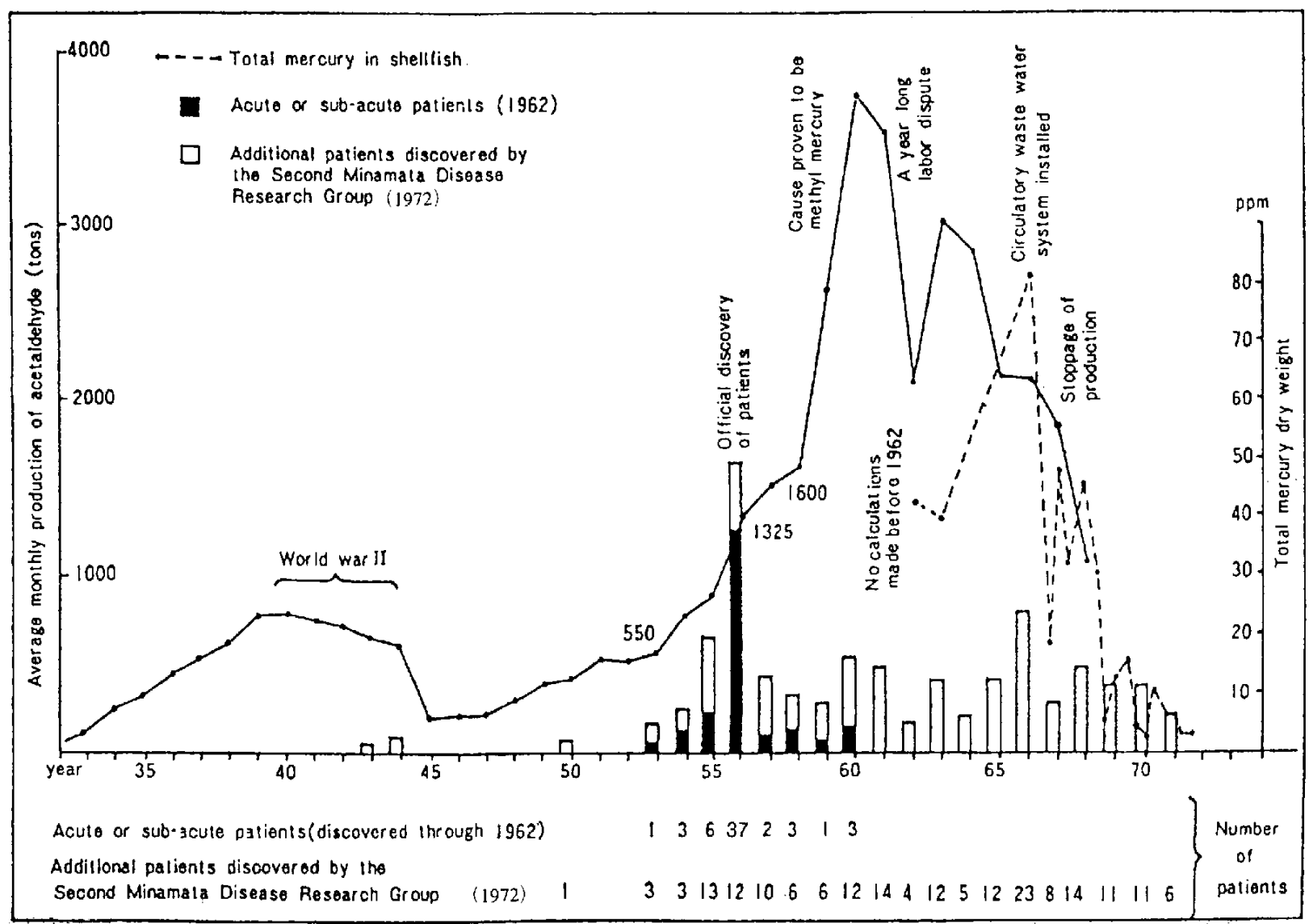

Fig. 1. Comparative chart of acetaldehyde production rate, onset of Minamata disease, and mercury content in the shellfish in Minamata Bay.

hospital and the local medical association uncovered 30 cases, and it was found that many of these people had been ill since 1953, and that most lived in the fishing villages of Minamata. They had been diagnosed variously as having encephalitis Japonica, alcoholism, hereditary ataxia and a number of other suspected diseases. Because the outbreak was endemic, it was immediately suspected to be an infectious disease and was treated as such.

In August, 1956, the Minamata Disease Study Group of the Kumamoto University School of Medicine was organized to investigate the cause of the outbreak. This group made public its interim -report on October, 1956. It reported that the disease was not infectious, and that it was a type of heavy-metal poisoning caused by eating the fish and shellfish from Minamata Bay. The number of patients continued to increase rapidly. By late 1956 there were 52 known victims. At the time, the Chisso waste water included various poisons: manganese, thalium, arsenic, mercury, selenium, copper and lead. The Kumamoto University Study Group found it necessary to conduct clinical, pathological, and experimental research on each substance ${ }^{1)}$. At first manganese was suspected, and then selenium and thalium were suspected ${ }^{2)}$. Although large amounts of each of these substances were detected in the environment and in autopsied patients, experiments with cats showed that none of these substances produced the same symptoms as the strange disease. Experiments were begun on the possibility that the causal element was a combination of several substances. Results, however, were negative. Even though the Study Group had not found the causal element, their experiments in 1957 began to prove the severity of contamination. When fish from Minamata Bay were fed to cats, Minamata disease symptoms were produced in them. In one experiment, a group of cats were fed three times a day, and each meal of each cat was supplemented with about 40 tiny fish caught in Minamata Bay, weighing a total of 10 grams per meal. Within an average of 51 days all the cats showed the symptoms of Minamata disease ${ }^{3)}$.

As a result of detailed clinical examinations of patients, characteristic symptoms were found to be as follows: there were no prodominal symptoms or fever. Symptoms began with a numbness of the ex- 


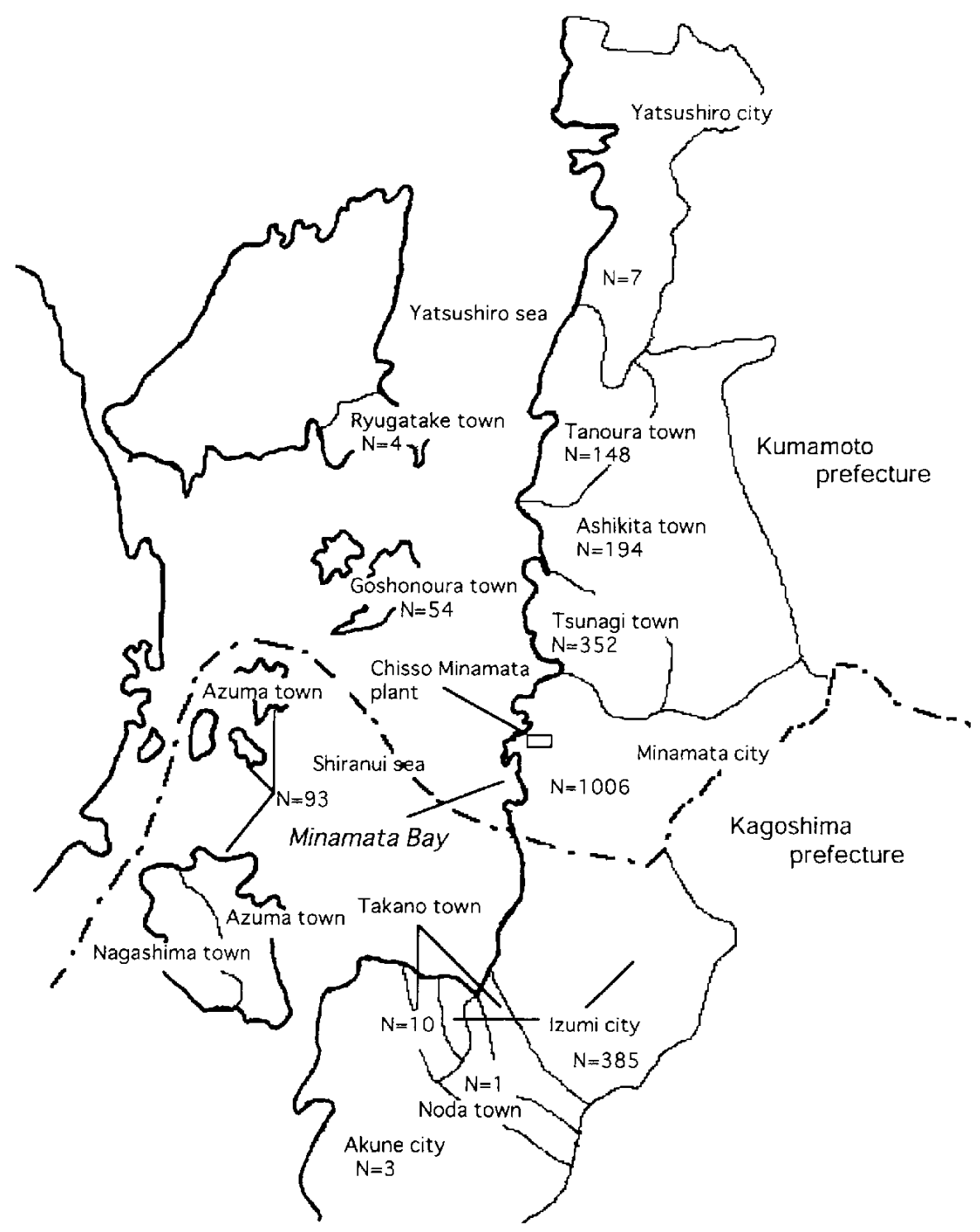

Fig. 2. Distribution of outbreaks of certified patients (Mar. 1994).

tremities, difficulty in hand movements and in grasping thing as when buttoning buttons, holding chopsticks, and writing. There was also a lack of coordination, sensory disturbance, weakness and tremor, dysarthria, ataxic gait, then disturbances of sight and impaired hearing. These symptoms gradually increased and finally caused general paralysis, deformity, difficulty in swallowing, convulsion and even death. Of the first 52 patients discovered, 21 died within one year of the onset of the disease ${ }^{4)}$. Pathological findings were as follows: there was general damage to the neurons of the cerebral cortex. The damage was especially severe in the calcarine regions of the occipital lobe, the precentral cortex of the frontal lobe and the postcentral cortex of the parietal lobe. Granular celltype atrophy in the depth of the cortical sulci was observed. While the Purkinje cells were more resistant to the intoxicant, they commonly disintegrated if heavily affected. The disappearance of granule cells characteristic of this poisoining occurred in the central portions of the cerebellum. The peripheral nerve fibers of the extremities, posterior root and the column were selectively affected. The cerebral nuclei, brain stem and spinal cord revealed no remarkable lesions except for demyelination and gliosis of the pyramidal tracts ${ }^{5)}$.

Then in 1958 members of the Study Group found that clinical and pathological findings in cases of Minamata disease coincided with certain cases of methyl mercury poisoning in England reported in 1940 by D. Hunter and D. S. Russell and published in a monograph on occupational toxicology ${ }^{6-9}$. The English cases involved the poisoning of workers 
in a factory producing methyl mercury pesticide. The Kumamoto University researchers began experiments with methyl mercury compounds. Cats who were fed some methyl mercury compounds directly showed the same symptoms as those cats affected with Minamata disease after eating the fish and shellfish from Minamata Bay. The University researchers also conducted an environmental survey of mercury for the first time. Findings showed in 1959 that there was an extraordinarily high level of mercury contamination in Minamata Bay: 2,010 $\mathrm{ppm}$ in the mud near the drainage channels of Chisso, the content gradually declining with the distance from the channel ${ }^{10)}$. Fish and shellfish sampled in Minamata Bay showed high mercury content. A high concentration of mercury was found in the internal organs of 23 patients who died of Minamata disease. The greatest amount was detected in the liver and kidneys. Although the amount in the brain was less than in the liver and kidneys, deposits were sufficient to cause severe brain damage; a characteristic of methyl mercury intoxication is that methyl mercury passes the blood-brain barrier more easily than does inorganic mercury, thus the amount deposited in the brain is larger than it would be in the case of inorganic mercury intoxication ${ }^{11)}$.

In July, 1959, an official statement by the Study Group was published: Minamata disease was considered to be a disease of the central nervous system, being caused by the intake of fish and shellfish taken from Minamata Bay, and special attention was called to mercury as the probable toxicant contaminating the fish and shellfish. Later, in 1960 , a methyl mercury compound in crystalline form was extracted from shellfish which had caused Minamata disease ${ }^{12)}$. The causal substance, methyl mercury, was now clear. At that point, however, Chisso counterargued that they used only inorganic mercury and not methyl mercury, in their production process, and therefore their factory could not be the source of the contamination. In spite of Chisso's non-cooperation, the Study Group managed to clarify at what point and in what way the inorganic mercury changed into methyl mercury, entered the food chain and eventually entered human beings through the fish. Finally, in 1962, the Study Group found in a laboratory, left over from the time when Chisso had been more cooperative, a bottle of sludge from the acetaldehyde process ${ }^{13)}$. Methyl mercury chloride was detected in the sludge, proving that the factory process itself had methylated the inorganic mercury.

\section{Occupational poisoning by methyl mercury and Minamata disease}

Minamata disease is methyl mercury poisoning. One of the important references which led to the discovery of its cause was a paper by $D$. Hunter and D. S. Russell as mentioned previously ${ }^{6,7}$ ). The paper described cases of methyl mercury poisoning of workers in a factory producing methyl mercury. The clinical and pathological findings in these cases coincided with those of Minamata disease.

Organic mercury compounds were first used as material in chemical experiments in 1863 , and the two technical assistants involved in those experiments thereafter suffered from central nervous system symptoms derived from organic mercury poisoning and died. Organic mercury was used in some types of medicines in the 1880s. Since 1914, organic mercury compounds have been produced as agricultural chemicals. In most of the cases of occupational poisoning, experimental researchers or their assistants were the first to suffer from these newly developed unknown chemical substances. Then workers who were engaged in the manufacturing of these substances suffered, and finally the users suffered from these commercial products. At last, large scale health effects occurred as a public hazard in a human ecosystem as shown in Table $1^{14-22)}$.

According to a paper written in 1930 by $\mathbf{H}$. Zangger who studied 110 cases of mercury poisoning from 1906 to 1930, there were two different types of poisoning, caused by inorganic and organic mercury respectively, and the neurological symptoms were remarkable in the latter type ${ }^{23)}$. He also pointed out that considerable care should be taken with regard to the newly developed chemical process producing acetaldehyde from acetylene by using inorganic mercury compounds as a catalyst. F. Koelsh who was a famous professor in the area of occupational health, described in a paper written in 1937 that he had seen cases of moderate poisoning due to methyl- and ethyl-mercury compounds produced as by-products in the acetaldehyde synthesization process, and that these cases disappeared with improvements in industrial hygiene ${ }^{24)}$. He also reported that the problem of organic mercury poisoning had begun to be observed in cases involving the production and use of organic mercury in seed dressings. These two papers preceeded those of D. Hunter and D. S. Russell. Furthermore the contents of these papers clearly suggested the origin of organic mercury compounds in the same manufacturing process as used in chemical plants such as in Minamata, but unfortunately these 
Table 1. Fatal cases of organic mercury poisoning

\begin{tabular}{|c|c|c|c|c|}
\hline $\begin{array}{l}\text { Reported } \\
\text { year }\end{array}$ & $\begin{array}{l}\text { Author } \\
\text { (country) }\end{array}$ & Preparation & Nature of work & $\begin{array}{l}\text { Number of } \\
\text { deaths }\end{array}$ \\
\hline 1865 & $\begin{array}{l}\text { Edwards } \\
\text { (U.K) }\end{array}$ & Dimethyl mercury & $\begin{array}{l}\text { Laboratory assistants } \\
\text { Preparing dimethyl } \\
\text { mercury amalgam }\end{array}$ & 2 \\
\hline 1940 & $\begin{array}{l}\text { Hunter et al. } \\
\text { (U.K) }\end{array}$ & $\begin{array}{l}\text { Methyl mercury } \\
\text { phosphate and nitrate }\end{array}$ & $\begin{array}{l}\text { Labourer in a chemical factory } \\
\text { Making seed dressings }\end{array}$ & 1 \\
\hline 1943 & $\begin{array}{l}\text { Hill } \\
\text { (Canada) }\end{array}$ & Diethyl mercury & $\begin{array}{l}\text { Stenographers } \\
\text { Working in office } 15 \mathrm{ft} \\
\text { away from store containing } 20,000 \text { Ibs }\end{array}$ & 2 \\
\hline 1948 & $\begin{array}{l}\text { Lundgren } \\
\text { \& Swensson } \\
\text { (Sweden) }\end{array}$ & $\begin{array}{l}\text { Fibrosan,alkyl } \\
\text { mercury compound }\end{array}$ & $\begin{array}{l}\text { Employed in impregnating timber with } \\
\text { fungicide }\end{array}$ & 1 \\
\hline 1948 & $\begin{array}{l}\text { Ahimark } \\
\text { (Sweden) }\end{array}$ & $\begin{array}{l}\text { Methyl mercury } \\
\text { hydroxide }\end{array}$ & Packing seed dressing & 2 \\
\hline 1954 & $\begin{array}{l}\text { Höök et al. } \\
\text { (Sweden) }\end{array}$ & Methyl mercury & $\begin{array}{l}\text { Control and service of seed dressing } \\
\text { plants and the sale of methyl mercury } \\
\text { compounds }\end{array}$ & 1 \\
\hline 1959 & $\begin{array}{l}\text { Kitamura et al. } \\
\text { (Japan) }\end{array}$ & Methyl mercury & $\begin{array}{l}\text { Population ingested methyl mercury } \\
\text { polluted fishes and shells }\end{array}$ & 21 \\
\hline 1963 & $\begin{array}{l}\text { Ul Hag et al. } \\
\text { (Pakistan) }\end{array}$ & $\begin{array}{l}\text { Agrosan, phenyl mercury } \\
\text { acetate. ethyl mercury } \\
\text { chloride. }\end{array}$ & $\begin{array}{l}\text { Farmers ingested organic mercury } \\
\text { polluted breads }\end{array}$ & 9 \\
\hline 1973 & $\begin{array}{l}\text { Bakir et al. }{ }^{20)} \\
\text { (Iraq) }\end{array}$ & $\begin{array}{l}\text { Methyl mercury } \\
\text { compounds }\end{array}$ & $\begin{array}{l}\text { Population ingested methyl mercury } \\
\text { polluted breads }\end{array}$ & 459 \\
\hline 1974 & $\begin{array}{l}\text { Derfan } \\
\text { (Ghana) }\end{array}$ & Ethyl mercury, BHC & $\begin{array}{l}\text { Farmers ingested mixed chemicals with } \\
\text { ethyl mercury and BHC polluted corn }\end{array}$ & 20 \\
\hline
\end{tabular}

papers were missed by the Study Group of Kumamoto University at that time. In any case, it is clear that occupational poisoning provides an important guide for investigation into the cause of an environmental disease.

Nevertheless, there are differences between the two types of poisoning as they occur under different conditions. This difference is important in understanding Minamata disease. Our knowledge of organic mercury poisoning prior to the outbreak of Minamata disease was based on occupational poisoning through direct exposure. In other words, occupational poisoning is a direct poisoning of workers which occurs under certain conditions, whereas Minamata disease involved the poisoning of the entire population of a contaminated area, including embryos, the aged and those who were already ill. Furthermore, it was an indirect poisoning through the food chain with environmental pollution as its medium. When these points are considered, it becomes clear that although Minamata disease and occupational poisoning coincide with each other in some respects they do not in others. Though they are caused by the same substance, their clinical symptoms differ, depending on whether the poisoning is acute, sub-acute or chronic. Poisoning affects the human body differently under different conditions in terms of the poison uptake (oral or inhalation), the amount of poison, and the length of exposure to it. Therefore, in reflection we later defined Minamata disease as encompassing every type of physical destruction caused by methyl mercury poisoning through environmental pollution extending from the past to the future. The physical destruction of the population brought about by Minamata disease was something that humanity had never experienced. The researchers at that time lacked a frame of reference which could have helped them come to a more speedy realization of the actual situation. That is one reason why there are still social and medical problems related to Minamata disease. Figure 3 is a diagram of the hypothetical relationship between methyl mercury contamination and Minamata disease. In the case of acute high-level methyl mercury contamination, the results are acute, wide-ranging brain symptoms including paralysis, convulsions, disturbance of consciousness, and finally death. In this type, the symptoms peculiar to Minamata disease are difficult to detect, as such cases show symptoms similar to those of encephalitis. In a slightly less serious case, the classical Hunter-Russell syndrome will appear. In a case of lower-level or long-term contamination, the symptoms vary, and the disease appears as an incomplete type, or a mild type, or an atypical case.

Let us now consider congenital Minamata disease $^{25)}$. If a woman is acutely ill with the disease, she does not become pregnant. In a less serious case, a miscarriage or stillbirth will occur ${ }^{26)}$. What is diagnosed as congenital Minamata disease 

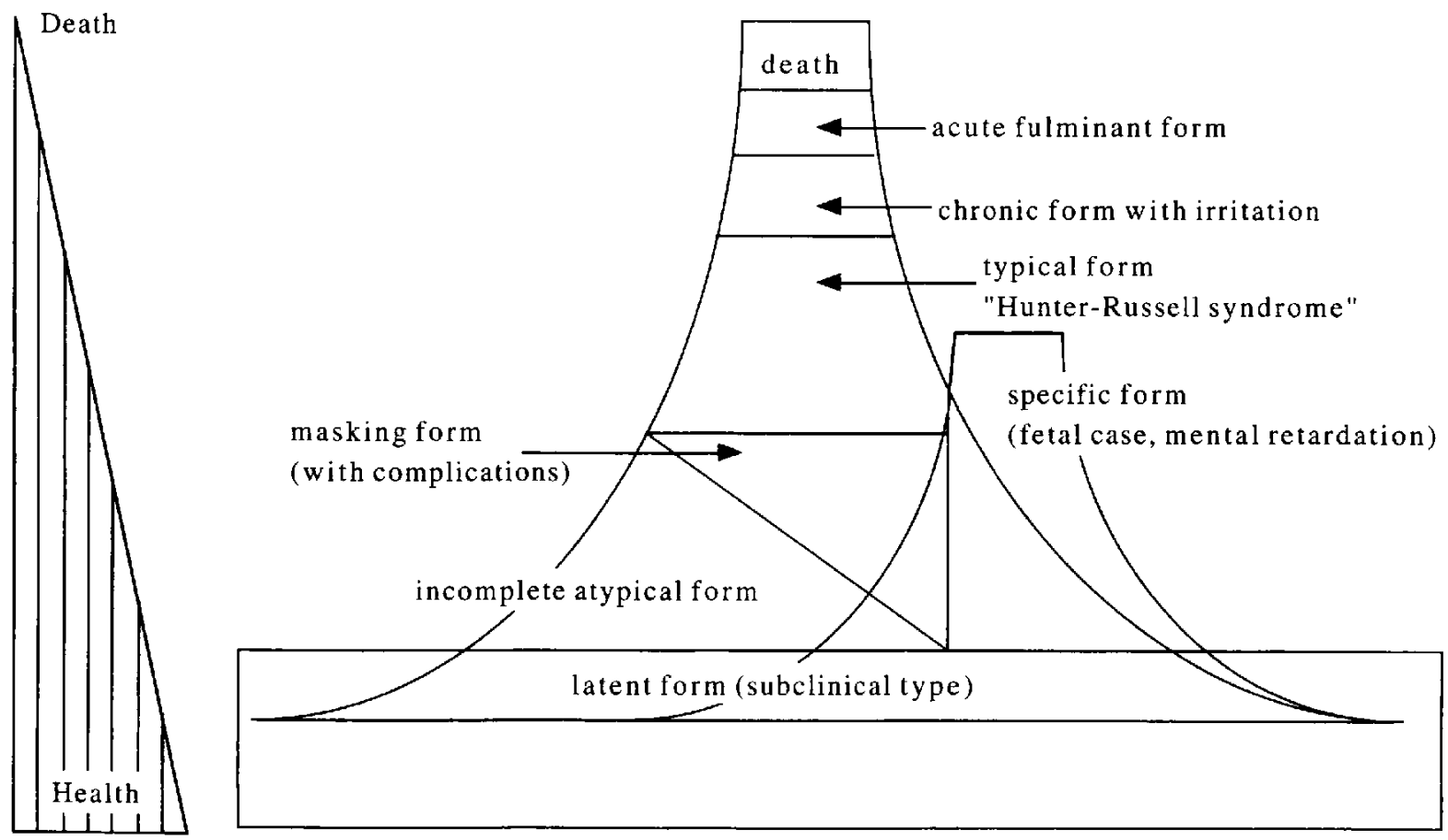

Fig. 3. Relationship between methyl mercury intake and symptoms.

at present are those cases in which the level of contamination is such that the mother does not lose her generative function and the child is born alive. In an even milder case, the disease may manifest as mental retardation. The International Programme on Chemical Safety reported that the clinical and epidemiological evidence indicated that prenatal life is more sensitive to the toxic effects of methyl mercury than is adult life $\mathrm{e}^{27}$.

Furthermore, since Minamata disease is caused by contamination of an area as a whole, including all of the inhabitants and families, there are naturally those who are already ill from other diseases. But the existence of other ailments such as senility, hypertension, spondylosis deformans, or diabetes, does not mean that there are no effects of methyl mercury. At Minamata and Niigata, first cats went mad and died, followed by a widespread outbreak of cases of severe brain damage symptoms, which led to the discovery of Minamata disease. This is the typical pattern of discovery of an environmental disease, but, in this pattern, discovery will be delayed if the pollutant is an unknown substance, if it involves a multiple contamination, or if it is a low-level contamination. The other method is to carry out a health survey of residents of a contaminated area and discover the deviation. This type of survey is indispensable in the case of longterm, low-level contamination or multiple contamination $^{28)}$.

\section{Dr. Hajime Hosokawa-Industrial Doctor of Chisso} factory

Dr. Hajime Hosokawa became director of the Chisso factory hospital in 1947. The Chisso factory hospital had become the central general hospital in this area. During this period, Dr. Hosokawa managed the mass health examination system for tuberculosis in cooperation with the Minamata health center, and promoted community medicine. He also performed research on the unclarified blood disease known as "Sennetsu (glandular fever)," under the guidance of the Department of Internal Medicine, Kumamoto University School of Medicine. He tended to be interested in community medicine.

As mentioned previously, on May 1, 1956, his staff reported to the Minamata health center: "An unclarified disease of the central nervous system has broken out." He undertook a vigorous program of house-to-house visiting research on this disease as a leader of the local medical association. By the autumn of 1956 , they had completed a preliminary report on this disease and they described the epidemiological and clinical features of this disease in detail (unpublished data). Their first report indicated the direction of the research to be undertaken by the Minamata Disease Study Group of the Kumamoto University School of Medicine. Following their initial field investigations, his research group performed an experimental study in which 
cats were fed fish caught in Minamata Bay. By the summer of 1959, it was almost certain that Minamata disease was caused by methyl mercury poisoning. Now, however, Chisso counterargued that they used only inorganic mercury and not methyl mercury in their production process, and therefore they could not be the source of the contamination. In spite of Chisso's non-cooperation, the Kumamoto University Study Group managed to find out at what point and in what way the inorganic mercury changed into organic mercury, entered the food chain, passed into fish, and then entered man. Chisso at that time was using a large amount of inorganic mercury in the acetaldehyde and vinyl chloride manufacturing processes. According to one later estimate, the total mercury dumped by Chisso could be between 200 and 600 tons $^{29}$.

Nevertheless, after the presentation of the mercury theory, Chisso became obstinate, and factory waste water became impossible to obtain for experimental purposes. Just at that time, by the end of 1959, Dr. Hosokawa had proven that the acetaldehyde sludge itself fed directly to cats caused the same symptoms as Minamata disease. He reported the fact to the director of the Chisso factory, and the director ordered Dr. Hosokawa to stop his experiments and not to publish his results. This fact was not made public for a long time. His situation as an industrial doctor was delicate and complicated under the severe social conditions surrounding the factory. Finally he resigned from Chisso factory in 1962 , and opened a clinic in his native city in Ehime prefecture. In 1965, Minamata disease reappeared in Niigata, and he immediately inspected the actual situation. He appealed to the management of the Chisso factory to make public their information but they refused. In 1970 he openly discussed all of his experimental procedures at the Chisso factory as a prosecution witness at a trial, only 3 months before he died of cancer. His life as an industrial doctor provides an impressive model that will be remembered forever.

\section{Lessons to be learned from Minamata disease}

Minamata disease has steadily been exerting its manifold and negative influences on the natural environment, on human health, and on the local community. No matter how much monetary compensation is paid, it is impossible to compensate the bereaved families for the sorrow over lost lives that will never return again. While keeping in mind that there are losses unmeasurable in terms of money, the major expenses borne by Chisso Corp. the polluter, and the government to overcome the effects of Minamata disease have now reached 250 billion yen. On the other hand, it is believed that it would only have cost Chisso Corp. approximately 400 million yen to install an appropriate drainage facility capable of preventing the outbreak of Minamata disease. Human actions which destroy the environment ultimately lead to great economic loss. It is unfortunate that the impact of Minamata disease has elucidated the fact that environmental destruction not only results in irreparable loss in human lives and health, but it has also shown that recovery of the local ecosystem and the local community is difficult even after a long period of time. In certain circumstances, it even threatens the very existence of a community. This is especially pertinent when we consider that developing countries have a tendency to promote short-term economic development at the expense of future environmental implications. However, these diseases and their grave social consequences can be avoided with the implementation of appropriate control measures. Dissemination of the knowledge that the same problem has already occurred elsewhere from the same basic causes is also of vital importance. In this respect, the exchange of views and experiences between countries can be a positive step toward avoiding similar catastrophes in the future. As one of the first tragedies of its type, Minamata offers the opportunity for the world to examine, learn, and avoid needless suffering.

\section{References}

1) Minamata Disease Study Group of Kumamoto University. Minamata Disease. Kumamoto : Shuei Shuppan, 1968.

2) McAlpine D, Araki S. Minamata Disease. An unusual neurological disorder caused by contaminated fish. Lancet $1958 ; 2: 629-631$.

3) Sera K, Matsunaga A, Sasaki T, et al. An experimental study on the causal element of an unclarified disease of the central nervous system in Minamata. J Kumamoto Med Soc 1957; 31 (Suppl): 307-310 (in Japanese with English abstract).

4) Tokuomi H, Okajima T, Kanai J, et al. Minamata disease. World Neurol $1961 ; 2: 536-546$.

5) Takeuchi $T$, Kambara T, Morikawa N, et al. Pathologic observations of the Minamata disease. Acta Path Jap 1959; 9 (Suppl) : 769-783.

6) Hunter D, Bomford RR, Russell DS. Poisoning by methyl mercury compounds. Quart J Med 1940; 9; 193-213.

7) Hunter D, Russell DS. Focal cerebral and cerebellar atrophy in a human subject due to organic mercury compounds. J Neurol Neurosurg Psychiatr 1954; 17: 235-241.

8) Pentschew A. Intoxicationen. Quecksilber vergiftung. In: Handbuch der Speziellen Pathologischen Anatomie and Histologie. Berlin: Springer Verlag, 


\title{
Minamata Disease from the Viewpoint of Occupational Health
}

\author{
Shigeru Nomura ${ }^{\dagger}$ and Makoto FutatsuKa \\ Department of Public Health, Kumamoto University School of Medicine \\ ${ }^{\dagger}$ Present affiliation: The Institute for Science of Labour
}

\begin{abstract}
Minamata Disease from the Viewpoint of Occupational Health: Shigeru Nomura, et al. Department of Public Health, Kumamoto University School of Medicine-Minamata disease is a neurological disorder caused by methyl mercury poisoning which occurred as the result of ingestion of large quantities of fish and shellfish polluted by industrial waste water in Minamata and Niigata, Japan. More than 40 years have passed since the epidemic was first reported in 1956 in Minamata. Inorganic mercury used as a catalyst in the acetaldehyde process had methylated inside the factory and had then been discharged into Minamata Bay. The waste from the acetaldehyde process continued to pour into the bay until 1968 . In the process of researching possible causal elements, the Minamata Disease Study Group of the Kumamoto University School of Medicine found that the clinical and pathological findings in cases of Minamata disease coincided with certain cases of methyl mercury poisoning in England reported in 1940 by D. Hunter and D. S. Russell and which were published in a monograph on occupational toxicology in 1958. The English cases involved the poisoning of workers in a factory producing methyl mercury pesticide. It is clear that occupational poisoning can provide an important guide for the investigation into the cause of an environmental disease such as Minamata disease but there are differences between the two types of poisoning as they occur under different conditions. Occupational poisoning is a direct poisoning of workers which occurs under certain conditions, whereas Minamata disease involves the poisoning of the entire population of a contaminated area, including embryos, the aged and those who are already suffering from other diseases. When these points are considered, it becomes clear that although Minamata disease and occupational poisoning coincide with each other in some respects, they do not in others.

(J Occup Health 1998; 40:1-8)
\end{abstract}

Received March 7, 1997; Accepted June 13, 1997

Correspondence to: M. Futatsuka, Department of Public health, Kumamoto University School of Medicine, 2-2-1 Honjo, Kumamoto 860, Japan
Key words: Minamata disease, Methyl mercury poisoning. Environmental health hazards, Occupational disease

Minamata disease is a neurological disorder caused by methyl mercury poisoning which occurred as the result of ingestion of large quantities of fish and/or shellfish polluted by industrial effluent in Minamata and Niigata, Japan. More than 40 years have passed since the epidemic was first reported in 1956. Inorganic mercury used as a catalyst in the acetaldehyde process had methylated inside the factory and had been discharged into Minamata Bay. The waste water from the acetaldehyde process continued to pour into the bay until 1968. Fish and shellfish accumulated methyl mercury in their body through the food chain. A comparative chart of acetaldehyde production rate, onset of Minamata disease, and methyl mercury content in the shellfish of Minamata Bay is shown in Fig. 1. By March, 1997, 2,222 persons had been certified as Minamata disease patients in this area by the Kumamoto and Kagoshima prefectural goverments. Areal distribution of the certified patients is shown in Fig. 2.

\section{The history of Minamata disease studies}

In April, 1956, a five-year-old girl was admitted to the pediatrics department of the Chisso Corporation's Minamata factory hospital with abnormal brain symptoms such as disturbance of gait and speech, and delirium. Within five weeks, her younger sister and four members of a neighboring family were found to be suffering from the same symptoms. On May 1, 1956, Dr. Hajime Hosokawa, a director of the Chisso factory hospital, reported to the Minamata health center: "An unclarified disease of the central nervous system has broken out." This is the official date of the discovery of what is now called Minamata disease. An immediate investigation by the Chisso factory hospital, the Minamata health center, the Minamata City 